\title{
The Effects of Weight-Bearing Exercise on Upper Extremity Activities Performance in the Female Stroke Patients
}

\author{
SungEun Lee \\ Department of physical therapy \\ Daegu University, Kyungsan, 712-714, South Korea \\ SungHyoun Cho \\ Department of physical therapy \\ Daegu University, Kyungsan, 712-714, South Korea \\ Kyoung Kim \\ Department of physical therapy \\ Daegu University, Kyungsan, 712-714, South Korea
}

\begin{abstract}
The purpose in the present study was to examine the effects of weight-bearing exercises on stroke patients' ability to perform upper extremity activities. Experiments were conducted with 24 female stroke patients who were randomly assigned to either a control group (CG) that performed general exercise or an experimental group that performed weight-bearing exercise (WBG). The experiments were conducted for 30 minutes per time, three times per week for six weeks. The upper extremity functions, grasping power, and the ability to manipulate the fingers were measured for both groups before the experiments and again six weeks after the beginning of the experiments. Although the scores for upper extremity functions relating to raising the arms that correspond to proximal upper extremity functions increased in both groups, the WBG showed more significant improvement. The WBG showed significant changes in grasping power compared to the CG. Based on these results, weight-bearing exercise can be effective in improving the ability to perform upper extremity movements and grasping power and thus can be used in stroke rehabilitation.
\end{abstract}

Keywords: Stroke, Weight bearing exercise, Upper extremity performance.

\section{INTRODUCTION}

Stroke is a disease that occurs when the blood supply to the brain is stopped or when a brain hemorrhage occurs, causing body motor disorders and a sudden disturbance of consciousness [1]. Among stroke-related motor disorders, upper extremity dysfunction is one of the most common sequelae. Among stroke patients, $30 \% \sim 60 \%$ have upper extremity dysfunction, even six months after the onset of stroke; in these cases, complete recovery cannot be expected [2]. The recovery of upper extremity functions is important because shoulder and hand motions are important in daily living and occupational activities. Permanent upper extremity dysfunction affects participation in social activities [3]. The upper extremity functions on a patients' stroke-affected side are regarded as the

\footnotetext{
* Corresponding author,Email : kykim257@hanmail.net Manuscript received Oct. 05, 2012; revised Feb 08, 2013, accepted Feb 18, 2013
}

most important factor in their prognosis and thus play an important role in the course of treatment [4].

Harris and Eng [5] found that the ability to perform upper extremity activities is closely correlated with upper extremity muscle strength, grasping power and upper extremity muscle tone. Park et al. [6] found that changes in the sensory functions of the affected side affected the motor ability of the upper extremities motor ability. And patients with subluxation could have serious upper extremity dysfunction [7]. In a study where patients used weight-bearing orthoses, Kinghorn and Roberts found that upper extremity weight-bearing activities were essential in the rehabilitation of patients with brain lesions [8]. Because upper extremities functions are very important in daily living activities, there continue to be studies about diverse treatment methods to recover motor skills and reconstruct nervous tissues [9]

Weight bearing of the upper extremity is essential in motions such as standing up by pushing a hand against the floor [10]. The controlled movements of the proximal regions required for fine hand motions are also developed through upper extremity weight 
bearing [11]. Weight bearing exercises are known to be effective for joint stability because they increase pressure on the joint to stabilize the humerus in the articular fovea, increase proprioceptive stimuli, and induce co-contraction of the muscles around the joint [12]. Upper extremity weight-bearing exercises include motions to support or push something with the hands and being in quadruped, prayer, and tripod positions [13].

Studies related to upper extremity weight-bearing have generally dealt with increasing bone density [14]. Studies analyzing kinetics and muscle activity during closed-chain exercises have also been conducted. Chen et al. [15] found that pressure on the joints and the activity of the muscles around the shoulders increased during floor-pushing postures in which one supports oneself with one hand and during crawling. Some studies indicate that if the bearing surface when crawling on all fours becomes more unstable, the activity of the muscles around the shoulders will increase $[13,15,16]$. Nawoczenski et al. [17] analyzed the kinetics of the scapulae of patients with spinal cord injuries during weight-bearing motions and reported that these motions were effective in relieving shoulder pain. Reistetter et al. [18] reported that bilateral weight-bearing conditions and patients' independent functions were significantly correlated. Therefore, it can be stated that upper extremity weight-bearing also affects patients' pain and functional activities. In this respect, upper extremity weightbearing activities can be considered a valuable therapeutic strategy to activate stroke patients' shoulder muscles and improve their functional activities.

In this study, the exercise was conducted among female stroke patients who need active weight bearing activity as they relatively have risk of decrease bone density. Therefore, female stroke patients are made to perform the upper extremity weightbearing exercises to examine the effects on the functions of their upper extremities' proximal regions, their grasping power and their ability to manipulate their fingers.

\section{SUBJECTS AND METHODS}

\subsection{Subjects}

The present study was conducted from January to April 2012 and involved 24 female stroke patients who had been diagnosed with stroke hemiplegia and were hospitalized or were receiving ambulatory treatment at rehabilitation hospital located in Daegu City, South Korea. The patients were randomly assigned to a WBG consisting of 12 patients or a CG consisting of 12 patients. We used random code method for random extraction where we set the code as 1 and 2, and executed drawing lots. The study subjects were limited to those who agreed to the study and who had been diagnosed with stroke hemiplegia using diagnostic equipment such as CT or MRI at least three months earlier. They were able to understand and comply with the study method, scored at least 24 points on the Korean version of the mini-mental state examination (MMSE-K). They had no orthopedic problems with any of their upper extremities, and were grade 2 or lower on the modified Ashworth scale (MAS), which measures spasticity. We sorted under MAS 2 stage that usually feel resistance in the range of passive movement, but able to move. We selected a group of people who are possible for weight support. The general characteristics of subjects were shown in Table 1.

Table 1. General characteristics of subjects

$(\mathrm{M} \pm \mathrm{SD})$

\begin{tabular}{cccc}
\hline \hline & $\begin{array}{c}\text { WBG } \\
(\mathrm{n}=12)\end{array}$ & $\begin{array}{c}\text { CG } \\
(\mathrm{n}=12)\end{array}$ & $\mathrm{p}$ \\
\hline $\begin{array}{c}\text { Age } \\
(\mathrm{yrs})\end{array}$ & $56.58 \pm 4.72$ & $58.83 \pm 6.65$ & .350 \\
$\begin{array}{c}\text { Height } \\
(\mathrm{cm})\end{array}$ & $158.00 \pm 2.95$ & $155.25 \pm 4.51$ & .090 \\
$\begin{array}{c}\text { Body weight } \\
(\mathrm{kg})\end{array}$ & $61.45 \pm 3.66$ & $64.40 \pm 5.37$ & .350 \\
$\begin{array}{c}\text { NIHSS } \\
(\text { score })\end{array}$ & $9.00 \pm 1.86$ & $8.92 \pm 1.88$ & .914 \\
$\begin{array}{c}\text { Time since } \\
\text { stroke (months) } \\
\text { Stroke type } \\
(\text { H/I })\end{array}$ & $12.33 \pm 5.03$ & $13.42 \pm 5.09$ & .605 \\
$\begin{array}{c}\text { Paretic side } \\
\text { Right/Left })\end{array}$ & $3 / 10$ & $3 / 9$ & \\
\hline
\end{tabular}

$\mathrm{M} \pm \mathrm{SD}:$ Mean \pm standard deviation

WBG: Weight-bearing group, CG: Control group

NIHSS: National Institutes of Health Stroke Scale

H: Hemorrhage, I: Infarction

\subsection{Experimental methods}

\subsubsection{Exercise methods}

Both the WBG and the CG performed kinesitherapy for 30 minutes including general gait training, body realignments, muscle strength exercises and exercises to increase the range of motion of joints. The WBG also performed upper extremity weight-bearing exercises based on methods introduced by Wang and Salem [14], Kim [19], Seong et al. [20], and Koo et al. [21]. Each patient in the WBG adopted a particular posture, maintained it for 10 seconds in one direction, and repeated the exercise 10 times. Since the subjects might not be able to quickly switch between postures, one posture was repeatedly adopted before adopting the next one. The exercises were performed for 20 minutes, with the patients repeating each item of the exercises five times in the first week of the experiment. The exercises were performed for 30 minutes in the second week and thereafter. The subjects were allowed to stop and rest immediately if they felt pain. The exercises were performed once a day, three times per week for six weeks. The exercises are described in [Table 2] [Figure 1-4].

Table 2. Weight-bearing exercise program

\begin{tabular}{ll}
\hline \hline \multicolumn{1}{c}{ Posture } & \multicolumn{1}{c}{ Exercise element } \\
\hline 1. Prone on elbow & $\begin{array}{l}\text { right/left weight shifting } \\
\text { back / forth weight shifting }\end{array}$ \\
\hline 2. Quadruped & $\begin{array}{l}\text { right/left weight shifting } \\
\text { back / forth weight shifting }\end{array}$ \\
\hline $\begin{array}{l}\text { 3. Sitting (bearing the } \\
\text { weight with the affected } \\
\text { hand placed on the floor) }\end{array}$ & $\begin{array}{l}\text { affected hand placed on the } \\
\text { floor, with the unaffected } \\
\text { hand placed on the affected }\end{array}$ \\
\hline
\end{tabular}




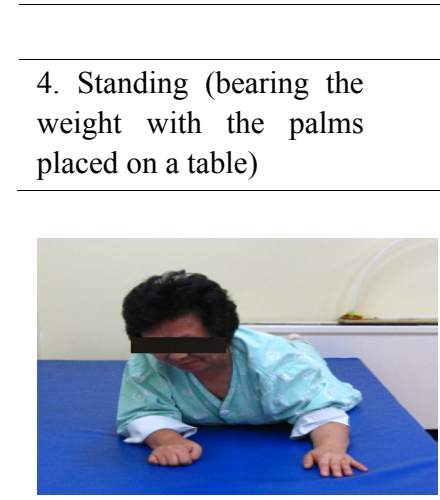

Fig. 1-1. Prone on elbow (Rt)

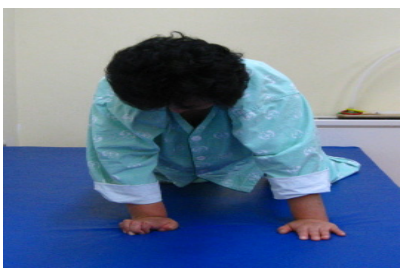

Fig. 2-1. Quadruped (Rt)

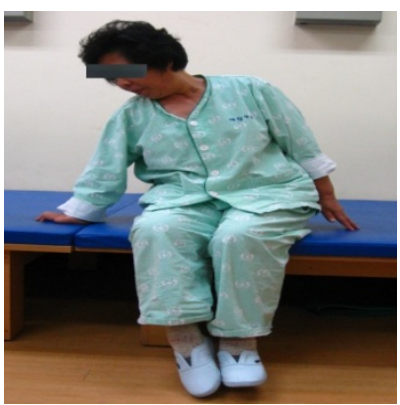

Fig. 3-1. Sitting pre-position

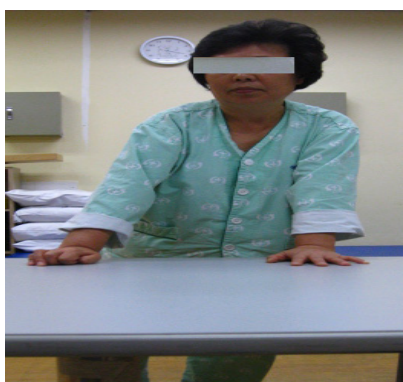

Fig. 4-1. Standing(Lt)

\section{hand}

right/left weight shifting back / forth weight shifting

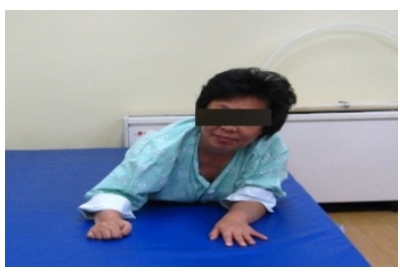

Fig. 1-2. Prone on elbow (Lt)

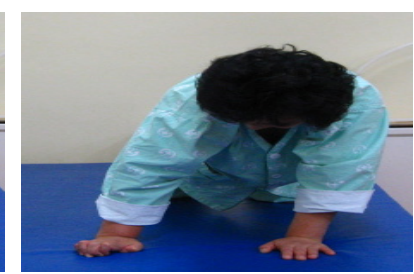

Fig. 2-2. Quadruped (Lt)

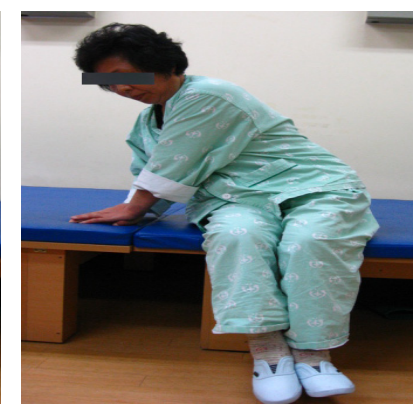

Fig. 3-2. Sitting post-position

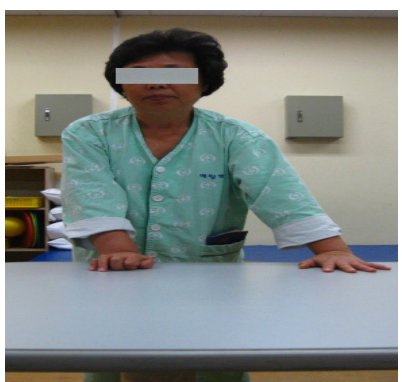

Fig. 4-2. Standing(Rt)

\subsubsection{Measurement tools}

Upper extremity functions were assessed using the Manual Function Test (MFT; SAKAI med, Japan) developed by Sakai Rehabilitation Instrument of School of Medicine, Tohoku University, Japan (Figure 5). This test tool was developed to measure and record changes in most functions of stroke patients' upper extremities during neurological convalescence. It consists of four proximal upper extremity assessment items, including upper extremity motility and four distal upper extremity assessment items, including grasping power and finger manipulation [22]. In the present study, we used the Korean version of the MFT translated by Kim [23]. Each test item is given 1 point when implemented and 0 points when not implemented. Therefore, a perfect score is 32 points and the total score is the total of the points given to all the items [23]. Manual function scores (MFS) scores were obtained by converting the MFT scores on the basis of a full score of 100 points. The upper extremity function tests were conducted once before performing the exercises and again six weeks after performing the exercises.

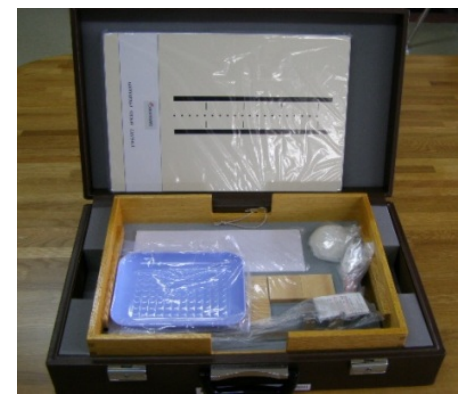

Fig. 5. Manual function test

\subsubsection{Statistical methods}

Measured data were statistically processed using SPSS Windows 12.0 (ICC, Chicago, USA). Changes in the performance of the upper extremity activities before and after the exercises for both the WBG and the CG were compared using paired $t$-tests. Differences in changes in the performance of the upper extremity activities before and after the exercises between the two groups were compared using independent $t$ tests. The statistical significance was set at $\mathrm{p}<.05$ for all the analyses.

\section{RESULTS}

\subsection{Comparison of manual function tests (MFTs) between the two groups}

Following are the MFT values of the two groups for before and after the exercises. There were no significant difference in the scores for upper limb motor, grasp power, finger manipulation between two groups before exercise ( $>$ >.05).

The mean MFS for the WBG after they performed the upper extremity exercises was $39.06 \pm 1.51$ and that of the CG was $28.12 \pm 2.87$. The difference between the two groups after the exercises was $10.93 \pm 3.25$ points, the score for the WBG was higher $(\mathrm{p}<.001)$. The mean MFS for grasping power after WBG performed the exercises was $11.71 \pm 1.09$ points and that of the CG was $5.98 \pm 2.01$ points. The difference between the two groups after the exercises was $5.72 \pm 2.29$ points, the score for the WBG was higher $(p<.05)$. The mean MFS for finger manipulation after the WBG performed the exercises was $14.06 \pm 2.59$ points and that of the CG was $11.71 \pm 3.00$ points. The difference between the two groups after the exercises was $3.24 \pm 3.97$ points, which is not statistically significant $(\mathrm{p}>.05)$ (Table 3). 
Table 3. Comparison of manual function tests (MFTs) between two groups

(unit: point)

\begin{tabular}{|c|c|c|c|c|c|}
\hline & Period & Group & $\mathrm{M} \pm \mathrm{SE}$ & $\mathrm{t}$ & $\mathrm{p}$ \\
\hline \multirow{4}{*}{ ULM } & \multirow{2}{*}{ Pre } & WBG & $25.00 \pm 1.88$ & \multirow{2}{*}{.05} & \multirow{2}{*}{.957} \\
\hline & & $\mathrm{CG}$ & $25.00 \pm 3.17$ & & \\
\hline & \multirow{2}{*}{ Post } & WBG & $39.06 \pm 1.51$ & \multirow{2}{*}{3.36} & \multirow{2}{*}{$.000^{* * * *}$} \\
\hline & & $\mathrm{CG}$ & $28.12 \pm 2.87$ & & \\
\hline \multirow{4}{*}{ GP } & \multirow{2}{*}{ Pre } & WBG & $6.77 \pm 1.07$ & \multirow{2}{*}{2.04} & \multirow{2}{*}{.053} \\
\hline & & $\mathrm{CG}$ & $5.46 \pm 1.72$ & & \\
\hline & \multirow{2}{*}{ Post } & WBG & $11.71 \pm 1.09$ & \multirow{2}{*}{2.49} & \multirow{2}{*}{$.026^{*}$} \\
\hline & & $\mathrm{CG}$ & $5.98 \pm 2.01$ & & \\
\hline \multirow{4}{*}{ FM } & \multirow{2}{*}{ Pre } & WBG & $13.54 \pm 2.35$ & \multirow{2}{*}{1.91} & \multirow{2}{*}{.068} \\
\hline & & $\mathrm{CG}$ & $11.45 \pm 2.86$ & & \\
\hline & \multirow{2}{*}{ Post } & WBG & $14.06 \pm 2.59$ & \multirow{2}{*}{.59} & \multirow{2}{*}{.561} \\
\hline & & $\mathrm{CG}$ & $11.71 \pm 3.00$ & & \\
\hline
\end{tabular}

WBG: Weight-bearing group, CG: Control group

ULM: Upper limb motor, GP: Grasp power

FM: Finger manipulation

\subsection{Comparison of manual function tests (MFTs) in each group}

There were significant differences for both the WBG and the $\mathrm{CG}$ in the upper extremity exercises consisting of raising the upper extremity forward, raising the upper extremity laterally, touching the back of the head with the palm, and touching the back with the palm, all of which corresponded to the proximal upper extremity assessment items $(p<.05)$. While the WBG showed significantly improved scores for upper extremity functions in terms of the control, the CG did not show a statistically significant improvement $(p>05)$. There were no significant increases in the scores for finger manipulation for either the WBG or the CG ( $>$.05) (Table 4).

Table 4. Comparison of pre-value and post-value for MFS on each group

(unit: point)

\begin{tabular}{lcrrc}
\hline \hline & Group & $\begin{array}{c}\text { Difference } \\
\mathrm{M} \pm \mathrm{SE}\end{array}$ & $\mathrm{t}$ & $\mathrm{p}$ \\
\hline \multirow{2}{*}{ ULM } & WBG & $14.06 \pm .98$ & -14.33 & $.000^{* * *}$ \\
& $\mathrm{CG}$ & $3.12 \pm .94$ & -3.31 & $.007^{* *}$ \\
\multirow{2}{*}{ GP } & WBG & $4.94 \pm .46$ & -10.65 & $.002^{* *}$ \\
& $\mathrm{CG}$ & $.52 \pm .35$ & -1.48 & .831 \\
\multirow{2}{*}{ FM } & WBG & $.52 \pm .35$ & -1.48 & .080 \\
& $\mathrm{CG}$ & $.26 \pm .26$ & -1.00 & .165 \\
\hline$* \mathrm{p}<05^{* *}: \mathrm{p}<01^{* * *}: \mathrm{p}<.001$ & &
\end{tabular}

$\mathrm{p}<.05,: \mathrm{p}<.01, \quad: \mathrm{p}<.001$
Difference $\mathrm{M} \pm \mathrm{SE}$ : Difference between pre-value and postvalue Mean \pm standard error

WBG: Weight- bearing group, CG: Control group

ULM: Upper limb motor, GP: Grasp power

FM: Finger manipulation
Stroke patients with neuromuscular adjustment problems will have functional limitations. Due to the non-use of paralyzed side and long hours on bed life, low bone density might lead into secondary problem of fracture. So active weight-bearing and strengthening exercises are conducted for them. However, research related to upper extremity weightbearing of stroke patients are mostly related to increase in bone density [14]. And research about the relationship between upper extremity weight-bearing activities and upper extremity functions are insufficient, so we thought it was necessary to study on this topic.

In a study where the electromyographic (EMG) activity of shoulder joint muscles during upper extremity weight bearing exercises was analyzed, Chen et al. [15] found that crawling postures increased the muscle activity of the lower trapezius muscle, the teres major muscle, the anterior fibers of the deltoid muscle, and the posterior fibers of the deltoid muscle. They also found that higher muscle activity occurred in exercises where the weight is borne by one hand compared to those where the weight is borne by both hands and when floor pushing pressure was applied by the palm compared to when the posture was maintained [15]. Tim et al. [24] reported that when 18 healthy adults performed upper extremity weightbearing exercises in isometric postures, muscle activity increased in postures that increased upper extremity weight bearing. Upper extremity weight-bearing activities promote the contraction of the rotator cuff and the scapula stabilizer muscles in the same way as closed-chain exercise performed with fixed distal parts [25]. It is thought that this improvement in muscle functions promoted increases in the stability of the scapula and the co-contraction of the muscles around the shoulder joints, resulting in improved upper extremity exercise MFSs related to the raising of the upper extremities.

In the comparing of grasping power MFSs within each group, the WBG showed a significant increase; the MFS increased from $6.77 \pm 1.07$ points before the exercises to $11.71 \pm 1.09$ points after the exercises. The CG did not show any significant increase; their MFS only increased from $5.46 \pm 1.72$ points before the exercises to $5.98 \pm 2.01$ points after the exercises. Regarding the between-group comparison after the exercises, the WBG had higher scores, which was statistically significant.

To improve grasping power, grasping should first be performed using controlled movements of the wrist extensor and the wrist flexor and appropriate isometric torques of the muscles should be generated to maintain the grasping posture. However, stroke patients experience changes in the biomechanical character-istics of muscles such as decreases in functional motor units, increased muscle cramping, and shortening of muscle fibers. These changes affect the generation of joint torques during isometric contractions when grasping is maintained [26]. In addition, stroke patients generally experience extension of the wrist joint extensor and shortening of the wrist joint flexor, which makes it difficult for them to secure appropriate lengths of their wrist extensor and flexor [27].

Xiaoling et al. [28] stated that if the co-contraction of joints and multi-joints increases, the muscle synergy of the affected extremity would decrease in order to perform separate movements of the upper extremities and that movement of the wrist on the affected side can be attempted in collaboration 
with movement of the elbow joint. One study investigated to determine the relationship between individual muscle strength variables and the capacity for functional movements using action research arm tests to assess the grasping, holding, picking, bending, and extending movements of the shoulder and elbow joints of 16 stroke patients. The authors reported that the grasping power of the patients' hands was closely related to elbow joint extension [29]. Mercier et al. [30] found that grasping power was greatly affected by elbow joint extension and was correlated with elbow joint weakening and shoulder joint flexion. Based on this, we believe the WBG's grasping power could be increased compared to that of the CG because the weight-bearing exercises included training to continuously maintain the extension of the elbow joint. Also, wrist joint extension postures were continuously maintained so that the shortened flexor could be extended and the extensor could be maintained at appropriate lengths, thus recovering the relationship between muscle length and tension.

Changes in finger manipulation MFSs before and after the exercises were not significant for either group. The WBG's score was $13.54 \pm 2.35$ points before the exercises and $14.06 \pm 2.59$ points after the exercises. The CG's score was $11.45 \pm 2.86$ points before the exercises and $11.71 \pm 3.00$ points after the exercises.

The difference in the changes between the two groups was also not statistically significant. Kim and Kang [31] conducted a study about improving upper extremity functions using biofeedback and suppression inducing exercises for the unaffected side. Although the range of motion of upper extremity joints and hand grasping power increased, hand functions and wrist extension functions did not, similar to the results of the present study. Caroline et al. [32] reported that patients' ability to pick up objects was not closely correlated with the ability to bend. Lee's study [33] reported that the results of fMRI imaging done after implementing bilateral learning exercises showed that finger exercises did not result in improvement. The reason improved results could not be obtained by the WBG group and the CG that implemented classical exercise programs is thought to be because only stimuli to increase the length of wrist-related muscles and tendons were given and no functional activity related to finger motion was performed.

The restriction of this research is that it is applied to patients whose shoulder joint is movable until the middle range and able to keep herself still resisting against gravity. The range for the selected group of people was restricted for generalization because it was based on females. Also, it has restrictions on the fact that it didn't research on changes related to dietary intake and taking medicine supplements. Therefore, there needs additional research on weight-bearing movement, control of exercise intensity and medicine effects according to the patients.

\section{CONCLUSION}

In the present study, the female stroke patients were asked to perform direct weight bearing exercises, and their ability to perform upper extremity activities were assessed. Given the study's results, it can be said that the upper extremity weightbearing exercises positively affects female stroke patients' ability to recover their capacity to perform upper extremity activities, such as grasping power. Therefore, we believed that the upper extremities' direct weight-bearing exercises can be used in addition to existing rehabilitation exercise programs in order to help stroke patients' recover their ability to perform upper extremity activities. Appropriate weight-bearing exercise programs should be developed, taking into consideration patients' shoulder subluxation, shoulder joint positions and hand contact surfaces.

\section{REFERENCES}

[1] S. A. Sharp, B. J. Brouwer, "Isokinetic strength training of the hemiparetic knee: effects on function and spasticity," Arch Phys Med Rehabil, vol. 78, no. 11, 1997, pp. 1231-1236.

[2] M. V. Radomski, and C. A. Tromly, Occupational Therapy for Physical Dysfunction, $5^{\text {th }} \mathrm{ed}$, Lippincott Williams \& Wilkins, Baltimore, 2002, pp. 1022-1035.

[3] I. Faria-Fortini, S. M. Michaelsen, J. G. Cassiano, and L. F. Teixeira-Salmela, "Upper extremity function in stroke subjects: relationships between the international classification of functioning, disability, and health domains," J Hand Ther, vol. 24, no. 3, 2011, pp. 257-264.

[4] C. E. Lang, D. F. Edwards, and R. L. Birkenmeier, "Estimating minimal clinically important differences of upper-extremity measures early after stroke," Arch Phys Med Rehabil, vol. 89, no. 9, 2008, pp. 1693-1700.

[5] J. E. Harris, and J. J. Eng, "Paretic upper-limb strength best explains arm activity in people with stroke," Phys Ther, vol. 87, no. 1, 2007, pp. 88-97.

[6] G. A. Park, S. J. Eun, M. J. Lee, and J. R. Hong, "The effect of functional improvement of upper limb on the performance of activities of daily livings in stroke patients," Society of Occupational Therapy for the Aged and Dementia, vol. 4, no. 1, 2010, pp. 29-38.

[7] J. C. Daviet, J. Y. Salle, M. J. Borie, M. Munoz, I. Rebeyrotte, and P. Dudognon, "Clinical factors associate with shoulder subluxation in stroke patients," Ann Readapt Med Phys, vol. 45, no. 9, 2002, pp. 505-509.

[8] J. kinghorn, and G. Roberts, "The effect of an inhibitive weight-bearing splint on tone and function: A single-case study," The American journal of Occupational Therapy, vol. 50, no. 10, 1996, pp. 807-815.

[9] A. S. Merians, D. Jack, R. Boian, M. Tremaine, G. C. Burdea, S. V. Adamovich, M. Recce, and H. Poizner, "Virtual realityaugmented rehabilitation for patients following stroke," Phys Ther, vol. 82, no. 9, 2002, pp. 898-915.

[10] S.-S. Bae, Movement patterns for rising from supine to erect stance, Doctoral thesis, Daegu Catholic University, 1995.

[11] K. Bobath, and B. Bobath, The neurodevelopmental treatment, In Scrutton D. ed, Management of the motor disorder of children with cerebral palsy, London: Spastics International Medical Publication, 1984, pp. 6-18.

[12] W. B. Kibler, and B. Livingston, "Closed-chain rehabilitation for upper and lower extremities," $J \mathrm{Am}$ Acad Orthop Surg, vol. 9, no. 6, 2001, pp. 412-421.

[13] M. Pontillo, K. F. Orishimo, I. J. Kremenic, M. P. McHugh, M. J. Mullaney, and T. F. Tyler, "Shoulder 
musculature activity and stabilization during upper extremity weight-bearing activities," N Am J Sports Phys Ther, vol. 2, no. 2, 2007, pp. 90-96.

[14] M. Y. Wang, and G. J. Salem, "The relations among upper extremity loading characteristics and bone mineral density changes in young women," Bone, vol. 34, no. 6, 2004, pp. 1053-1063.

[15] S. B. Chen, J. Y. Chang, and A. T. Hsu, "Kinetics and electromyographic analyses of shoulder during upper extremity weight-bearing exercises," Journal of Biomechanics, vol. 40, vol. 2, 2007, pp. 390.

[16] R. C. de Araújo, H. T. Tucci, R. de Andrade, J. Martins, D. Bevilaqua-Grossi, and A. S. de Oliveira, "Reliability of electromyographic amplitude values of the upper limb muscles during closed kinetic chain exercises with stable and unstable surfaces," J Electromyogr Kinesiol, vol. 19, no.4, 2009, pp. 685-694.

[17] D. A. Nawoczenski, L. M. Riek, L. Greco, K. Staiti, and P. M. Ludewig, "Effect of shoulder pain on shoulder kinematics during weight-bearing tasks in persons with spinal cord injury," Arch Phys Med Rehabil, vol. 93, no. 8, 2012, pp. 1421-1430.

[18] T. Reistetter, B. C. Abreu, J. Bear-Lehman, and K. J. Ottenbacher, "Unilateral and bilateral upper extremity weight-bearing effect on upper extremity impairment and functional performance after brain injury," Occup Ther Int, vol.16, no.3-4, 2009, pp. 218-231.

[19] J.-S. Kim. "Effect of upper extremity weight bearing on locomotion of infant with athetoid cerebral palsy," The journal of Korean society of physical therapy, vol. 8, no.1, 1996, pp. 1-14.

[20] S. C. Sung, and M. G. Lee, "Effects of resistance and balance exercise training on isokinetic function, postural stability, and balance efficacy in elderly women," Korean Journal of Sport Science, vol. 18, no. 4, 2007, pp. 21-33.

[21] B. O. Koo, E. Y. Kim, M. H. Park, M. C. Park, and J. M. Shim, "The effect on functional recovery of self exercise program in stroke," Journal of Special Education \& Rehabilitation Science, vol. 47, no.1, 2008, pp. 331-347.

[22] S. Miyamoto, T. Kondo, Y. Suzukamo, A. Michimata, and S. Izumi, "Reliability and validity of the manual function test in patients with stroke," Am J Phys Med Rehabil, vol. 88, no. 3, 2009, pp. 247-255.

[23] M.-Y. Kim, "A study of manual functional test for C.V.A," The Journal of Korean academy of occupational therapy, vol. 2, no. 1, 1994, pp. 19-26.

[24] L. Tim , J. Thomas, G. Carl, D. Scott, and J. Arthur, "Shoulder musculature activation during upper extremity weight-bearing exercise," J Orthop Sports Phys Ther, vol. 33, no. 3, 2003, pp. 109-117.

[25] S.-M. Kim, "The shoulder pain in hemiplegia after stroke," Ulsan College UC Report, vol. 27, no. 2, 2000, pp. 595-613.

[26] L. Ada, N. O'Dwyer, J. Green, W. Yeo, and P. Neilson, "The nature of the loss of strength and dexterity in the upper limb following stroke," Human Movement Science, vol. 15, no. 5, 1996, pp. 671-687.

[27] A. Shirley, Sahrmann, J. Barbara, and B. S. Norton, "The relationship of voluntary movement of spasticity in the upper motor neuron syndrome", Annals of Neurology, vol. 2, no. 6, 1997, pp. 460-465.

[28] X. Hu, K. Tong, V. S. Tsang, and R. Song, "Joint-angle dependent neuromuscular dysfunctions at the wrist in persons after stroke," Arch Phys Med Rehabil, vol. 87, no. 5, 2006, pp. 671-679.

[29] C. I. Renner, P. B. ungert-Kahl, and H. Hummelsheim, "Change of strength and rate of rise of tension relate to functional arm recovery after stroke," Arch Phys Med Rehabil, vol. 90, no. 9, 2009, pp. 1548-1556.

[30] C. Mercier, and D. Bourbonnais, "Relative shoulder flexor and handgrip strength is related to upper limb function after stroke," Clin Rehabil, vol. 18, no. 2, 2004, pp. 215-221.

[31] G. S. Kim, and J. Y. Kang, "Effects of upper extremity exercise training using biofeedback and constraintinduced movement on the upper extremity function of hemiplegic patients," Journal of Korean Academy of Nursing, vol. 33, no. 5, 2003, pp. 591-600.

[32] I. E. Caroline, P. Renner, P. Bungert-Kahl, and H. Horst, "Change of strength and rate of rise of tension relate to functional arm recovery after stroke," Arch Phys Med Rehabil, vol. 90, no. 9, 2009, pp. 1548-1556.

[33] M. H. Lee, W. K. Lee, and S. S. Bae, "The effect of repetitive bilateral arm training for the hemiplegic upper extremity in chronic phase after stroke," The Journal of Korean Society of Physical Therapy, vol.15, no. 3, 2003, pp. 519-536.

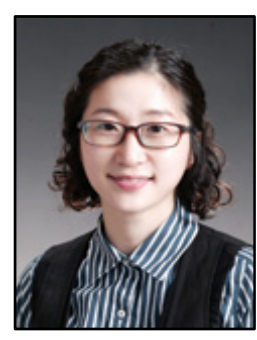

\section{Sung-Eun, Lee}

She received the degree of M.S. in the physical therapy in 2009 from Daegu university, Korea. And now she is being doctorate degree in physical therapy, Daegu university, Korea. Her main research interests include biomechanics and sports physical therapy.

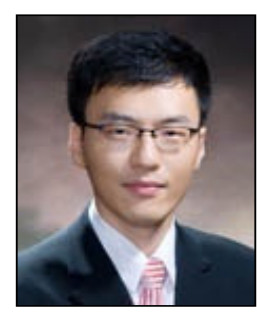

\section{Sung-Hyoun, Cho}

He received the degree of M.S. in the physical therapy in 2010 from Daegu university, Korea. And now he is being doctorate degree in physical therapy, Daegu university, Korea. His main research interests include biomechanics and therapeutic exercise.

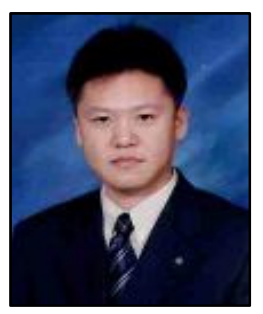

\section{Kyoung, Kim}

He received the degree of M.S. in the physical therapy in 2000 from New York university, USA. And he received the degree of Ph.D. in the physical therapy in 2005 from Sahmyook university, Korea. Since 2006, He is a professor in the department of physical therapy from Daegu university, Korea. His main research interests include cardiovascular and pulmonary physical therapy, physical therapy evaluation tools development. 